\title{
Mudanças das Ecologias de Aprendizagem das crianças à luz das Tecnologias Digitais
}

\author{
Patrícia Fernanda da Silva ${ }^{1}$, Crediné Silva de Menezes ${ }^{1}$, Léa da Cruz Fagundes ${ }^{1}$ \\ ${ }^{1}$ Programa de Pós-Graduação em Informática na Educação (PPGIE) \\ Universidade Federal Rio Grande do Sul (UFRGS) \\ Av. Paulo Gama, 110 - Farroupilha, Porto Alegre - RS, 90046-900 - RS - Brazil
}

\begin{abstract}
This paper describes a research which investigated the changes in children's Learning Ecologies in the light of digital technologies. Therefore, the methodology used was the application of Piagetian tests and later the realization of tests using technological resources. For the children's observations and interactions, the Clinical Method was used. During the research, it was observed that technologies enable children to perceive things more easily than when using concrete material, as well as that they can learn in different contexts and informal environments, based on their interactions, experiences and exchanges. of experiences with each other.
\end{abstract}

Resumo. Este artigo descreve uma pesquisa que investigou sobre as mudanças das Ecologias de Aprendizagem das crianças à luz das tecnologias digitais. Para tanto, a metodologia utilizada foi a aplicação de provas piagetianas $e$ posteriormente a realização de provas com uso de recursos tecnológicos. Para as observações e interações das crianças foi utilizado o Método Clínico. Durante a pesquisa, foi possivel observar que as Ecologias de Aprendizagem têm se modificado e possibilitado às crianças diferentes formas de aprender à luz das Tecnologias Digitais, com diferentes pessoas, contextos informais, a partir das suas interações, experiências e vivências adquiridas, o que lhe permite escolher, desenvolver a autonomia e o protagonismo.

\section{Introdução}

Vivemos em um contexto de grandes transformações sociais, culturais e principalmente tecnológicas. Atualmente, percebe-se que crianças, adolescentes, jovens e adultos estabelecem uma relação muito dinâmica com smartphones e tablets, fazendo com à forma de ensinar e aprender se modifique.

De acordo com os indicadores apontados através da pesquisa realizada pelo Comitê Gestor da Internet (CGI) e o Centro Regional de Estudos para o Desenvolvimento da Sociedade da Informação (Cetic.br), a TIC KIDS ONLINE - Brasil de 2015, com 3068 famílias entrevistadas de diferentes regiões do Brasil, considerando pais, crianças e adolescentes entre 9 a 17 anos; de 29,7 milhões nesta faixa etária, 23,7 milhões, 80\% são usuários da internet, utilizando de forma intensa, com acesso mais de uma vez por dia.

O principal dispositivo para acesso a rede é o telefone celular: - $83 \%$ acessam por meio dele, 1 em cada 3 crianças ou adolescentes se conectam a internet somente por meio do telefone, o equivalente a $31 \%$ da amostra - uma ferramenta acessível que tem oportunizado 
estar conectado, interagindo e desempenhando diferentes funções. Uma nova forma de fazer e comunicar-se vem se mostrando disponível e ao alcance das crianças cada vez mais cedo.

Nesta perspectiva, é importante observar como as Tecnologias Digitais podem ser inseridas em contextos de aprendizagem, oferecendo recursos e ferramentas diferenciadas, além de novas oportunidades para aprender, reaprender e perceber as coisas. Cabendo observar o modo com que as tecnologias digitais chegam até as crianças, bem como estão despertando seu interesse e proporcionando verificar fatos de forma mais fácil do que quando exploram objetos reais.

Visando encontrar respostas para esta problemática e observar as mudanças nas Ecologias de Aprendizagem, são trazidas situações que foram observadas e percebidas durante o desenvolvimento de uma pesquisa com crianças de 7 meses a 7 anos de idade, a partir da aplicação de provas Piagetianas com e sem o uso das tecnologias. Após a aplicação das provas Piagetinas, foram analisadas as mudanças das Ecologias de Aprendizagem à luz das Tecnologias Digitais.

Este artigo está estruturado da seguinte forma: uma breve introdução, metodologia de trabalho e o desenvolvimento do mesmo, o referencial teórico utilizado para dar suporte à pesquisa e o seu desenvolvimento, trabalhos correlatos, uso das provas piagetianas e dos recursos tecnológicos, resultados obtidos e para finalizar as considerações finais e o referencial bibliográfico utilizado para dar suporte ao trabalho.

\section{Metodologia de trabalho: o uso do Método Clínico, as provas piagetianas e as aproximações com as tecnologias digitais}

Piaget elaborou um grande número de provas para constatar o progresso do desenvolvimento cognitivo de crianças e adolescentes em relação à conservação, seriação, volume, massa, dentre tantas outras. Nessas investigações, desenvolveu o Método Clínico, em que é possível identificar como o sujeito evolui sobre determinadas noções.

Através do Método Clínico, o pesquisador busca analisar pela verificação da estrutura de um estado de desenvolvimento ou de processo de estruturação mental na resolução de problemas, os mecanismos mais profundos do pensamento. Deste modo, caracteriza-se pela coleta de dados pela proposição de atividades específicas, observação, registro e análise de diálogos com a criança que serão mediados pelo experimentador, visando seguir seu pensamento sem perder nenhum detalhe, mediante à análise dos dados que foram registrados (Deval, 2002).

O estudo dos dados obtidos, trata-se de um estudo múltiplo inspirado pelo Método Clínico (Piaget, 1975). Optou-se pela inspiração no Método Clínico, devido à variedade de opções na observação e coleta de dados, a qual oportuniza uma diversidade de estratégias para o registro.

Para investigar as mudanças das Ecologias de Aprendizagem das crianças à luz das Tecnologias Digitais, utilizou-se à aplicação de provas Piagetinas e posteriormente o desenvolvimento das mesmas provas com uso de recursos tecnológicos, comparando os resultados para verificar como à percepção das crianças se modifica diante da mudança de recursos.

Durante a pesquisa, foram observadas 16 crianças, entre 7 meses a 7 anos nesse estudo múltiplo. Buscou-se observar 2 crianças de cada faixa etária, 8 meninas e 8 meninos, de famílias com classes sociais distintas, com os pais com diferentes graus de instrução e profissão, para que os dados pudessem ser os mais diversificados, as observações 
aconteceram na residência das crianças, ao término seus pais eram entrevistados, relatando como estavam percebendo a exploração das tecnologias digitais pelos seus filhos.

\section{As Ecologias de Aprendizagem}

Jacson (2013) salienta que as Ecologias de Aprendizagem de um indivíduo abrangem diferentes contextos, relacionamentos e interações, oferecendo oportunidades e recursos para aprendizagem. Adicionalmente, salienta que esta é uma característica de ambientes educacionais formais e informais. Onde no ambiente formal a ecologia é proposta pela própria instituição e pelos professores, enquanto no ambiente informal, as ecologias são propostas por pessoas que realizam mediações ou mesmo grupos que possuem cunho educacional.

As crianças ao iniciar suas vivências começam a aprender em um contexto ecológico, interagindo em casa, com seus pais, com outras crianças e com adultos os quais convive. Nestes ambientes ela aprende, desaprende e reaprende, pois à medida que interage consegue realizar constatações e recolher informações que podem ser modificadas ou aprimoradas.

Ao propor uma Ecologia de Aprendizagem em ambiente formal, espera-se que o sujeito possa utilizá-la em diversos ambientes, e até mesmo propor as suas próprias ecologias, através de interações entre um vasto número de processos e relacionamentos.

As Ecologias de Aprendizagem oferecem dimensões de tempo e espaço, proporcionando diferentes conexões entre contextos e locais ao longo da vida. Além disso, possibilitam sustentar a criação de como aprender em diferentes meios e fases de vida, integrando experiências e aprendizado em diversos aspectos.

Pelos estudos das ecologias, foi possível perceber que a aprendizagem acontece em espaços físicos e virtuais, criadas em ambientes e contextos sociais (LEMKE, 1997). Além disso, ocorre em diferentes espaços de tempo, podendo conectar presente, passado e futuro.

As Ecologias de Aprendizagem conectam-se, modificam-se e evoluem a partir de novas ideias e entendimentos, configurando assim, novas oportunidades de aprendizagem. À medida que estas mudanças acontecem, nosso sistema também se modifica, agindo de forma diferenciada em cada etapa, o que prepara o sujeito para passar pelas demais.

O processo de aprender não é limitado somente ao conteúdo, estrutura e avaliação, mas também pelas diversas motivações e desejos de aprender sobre algo, possibilitando criar um objetivo e uma ecologia pessoal para aprender, englobando todas as oportunidades possíveis de aprendizado, sejam elas criadas pelo próprio sujeito ou oportunizadas pelo meio.

Para aprender sobre algo o sujeito interage de forma organizada com o seu contexto social, podendo ser auxiliado por um profissional ou mesmo por pessoas nas quais tem alguma relação. As habilidades são desenvolvidas juntamente com o conhecimento prático, teórico e demais experiências que adquire ao interagir com o objeto de conhecimento. Durante este processo o sujeito necessita ter domínio de conhecimento processual, incorporação de conhecimentos reais e ainda o desenvolvimento de habilidades, para que futuramente tenha condições de criar as suas Ecologias.

\section{Os estágios de desenvolvimento conforme Piaget}

Piaget (1974), ao falar de Epistemologia Genética salienta que o conhecimento é construído a partir da interação entre o sujeito e o objeto. Ao agir sobre objetos, uma experiência física acontece, propriedades abstratas são extraídas dos objetos e das ações, bem como suas características e informações. 
Piaget durante suas pesquisas elaborou um grande número de provas para constatar o progresso do desenvolvimento cognitivo de crianças e adolescentes em relação à conservação, seriação, volume, massa, dentre tantas outras. Em meio a essas investigações, desenvolveu o Método Clínico, um método que possibilitava identificar como que o sujeito evoluia diante de determinadas noções.

Durante suas pesquisas, ficou evidente que as crianças não nascem prontas, à medida que crescem desenvolvem o seus sistema biológico, apresentando características que são pertinentes de determinados estágios de desenvolvimento.

\subsection{O Estágio Sensório Motor (0 a mais ou menos 2 anos)}

Primeiro estágio da criança, vai do nascimento até mais ou menos os 2 anos. É um estágio em que não estão presentes as representações, a linguagem e os conceitos. O aparecimento da função simbólica e da linguagem dão início a um estágio que se estende até o momento em que a criança começa um pensamento simbólico e pré-conceitual.

Durante este estágio, suas ações consistem em coordenar entre si percepções e movimentos sucessivos, os quais são reconstituídos pelo pensamento. Por volta do final do segundo ano de vida, a criança começa a adquirir a linguagem sistematicamente. Este fato se deve a utilização do sistema dos sinais verbais que são exercitadospor uma "função simbólica" (Piaget 1976) mais geral, que permite representar o real através de "significantes" diferentes das coisas "significadas".

A linguagem é adquirida ao mesmo tempo em que o símbolo é formado, sendo que ao empregar signos e símbolos presume-se que a criança esteja apta, pois esta ação se mostra totalmente nova diante de outras condutas sensório-motoras em que elarepresenta uma coisa por outra.

\subsection{O Estágio Pré-Operatório ( 2 a mais ou menos 7 anos)}

Caracteriza-se pelo primeiro estágio da inteligência pré-conceitual, pré-conceitos ou raciocínio pré-conceitual, quando a linguagem começa a aparecer até mais ou menos 4 anos.

Por volta dos 9 a 10 meses, um esquema sensório-motor é elaborado e prepara as operações concretas que irão ocorrer por volta de 2 a 7 anos. Neste estágio, o objeto se internaliza e é lembrado pela criança, mesmo após o seu desaparecimento.

A criança reconstrói o objeto, o espaço e o tempo, categorias lógicas de classes e de relações no plano de representação. Os estágios entre os 2 e 7 anos tornam-se uma extensão dos estágios sensórios-motores, formando as bases das posteriores operações concretas.

Neste estágio, a criança apresenta dificuldades em elaborar relações compostas entre si, pois a ação continua sendo traduzida com o único sentido da imagem e também a assimilação é centrada na percepção. Ainda não existe identidade correta dos elementos, conservação do todo, composição transitiva, reversível e associativa.

A intuição evolui, a criança passa a observar e reinventar relações que antes eram desprezadas, favorecendo a possibilidade de retorno e dos pontos de vista. As intuições descentradas conduzem ao caminho das regulações, que tendem à reversibilidade, à composição transitiva e à associatividade, e em geral da conservação através de pontos de vistas. Desta forma, o progresso das intuições conduz para a mobilidade reversível e prepara para a operação.

\section{Trabalhos correlatos}


Durante o desenvolvimento deste trabalho buscou-se observar quais as pesquisas que estavam sendo realizadas sobre as Ecologias de Aprendizagem à luz do uso das Tecnologias Digitais por crianças na primeira infância e como vinham abordando este assunto, haja vista que à referida pesquisa foi desenvolvida entre 2016 e 2017.

Os materiais foram pesquisados a partir da plataforma Scopus, do Portal Capes, Catálogo Online Sabi, Repositório Digital Lume, Web of Science e CBIE, foram considerados registros de 2015 a 2017 a partir da busca "Criança", "Tecnologia" e "Ecologias de Aprendizagem".

$\mathrm{Na}$ plataforma Scopus, foram encontrados trabalhos referentes às Ecologias de Aprendizagem para o desenvolvimento da linguagem, formação de professores para atuar em espaços Maker, e também trabalhos sobre Ecologias Sociais.

O Portal de Periódicos da Capes trouxe somente um registo, em que era apresentada uma pesquisa sobre a Ecologia de Aprendizagem das famílias diante de um determinado game para meninas. Os anais do CBIE de anos anteriores apresentaram as Ecologias de Aprendizagem e as Tecnologias Digitais voltadas à formação de professores e as suas expectativas diante das abordagens, todas tendo como público alvo os adultos.

Os assuntos mais abordados nas demais plataformas foram o uso de ferramentas com crianças em idade pré-escolar, o uso da internet, abordagens com o uso de computadores, as práticas e abordagens pedagógicas desenvolvidas com crianças, porém não abordavam as Ecologias de Aprendizagem à luz das Tecnologias Digitais, traziam abordagens somente das tecnologias. Ao refinar a busca, definindo trabalhos publicados à partir de 2017, não foram encontrados registros sobre o referido assunto.

A maior preocupação dos autores em geral tem sido utilizar as tecnologias como uma ferramenta para que a criança possa melhor compreender e construir conhecimentos, a partir da exploração das tecnologias, servindo como apoio para efetivar aprendizagens. Afirmam, ainda, que em diferentes situações de exploração das tecnologias digitais, as crianças tiveram ganhos positivos em relação a aprendizagem, no entanto não deixam claro o que faz com que as crianças tenham estes ganhos.

Percebe-se por parte dos autores uma grande preocupação em relação ao uso das tecnologias, pois buscam exemplificar e apoiar práticas pedagógicas relatando suas intervenções e sucessos no trabalho com crianças.

\section{Desenvolvimento da pesquisa: as provas piagetianas e uma aproximação com materiais digitais}

Participaram desta pesquisa, 2 (duas) crianças de cada faixa etária, dos 7 (sete) meses aos 7 (sete) anos, totalizando em 16 (dezesseis) crianças.

Para a escolha, foram selecionadas crianças com idades distintas, que utilizavam as tecnologias digitais, de diferentes classes sociais, e tendo os pais com diferentes graus de instrução. A interação com sujeito foi organizada em três momentos: aplicação da prova ou verificação de observações realizadas por Piaget; aplicação de uma atividade utilizando tecnologias digitais e por fim, uma conversa com os pais para obter mais informações sobre a criança.

As observações realizadas e as provas de Piaget, foram de acordo com a faixa etária dos sujeitos. Para as crianças a partir de 7 meses até foi realizada a prova de permanência de 
objetos e imitação, posteriormente foi utilizada uma programação em Scratch em que o gato desaparecia da tela ${ }^{1}$ e também o bichinho interativo da Totetoy ${ }^{2}$.

Os sujeitos a partir de um ano experimentaram a programação em Scratch, mas posteriormente foram observados realizando imitações e utilizando o bichinho interativo da Totetoy.

Para as crianças de 2 anos foram oportunizadas situações de observação durante suas brincadeiras e também atividades de classificação, em que deveriam classificar formas geométricas criadas com E.V.A. O recurso tecnológico foi explorado no tablet com os aplicativos Classificação - Jogos para Crianças ${ }^{3}$ e Bimi Bo Formas e Cores ${ }^{4}$, em que as crianças deveriam levar as formas geométricas até os seus respectivos lugares, observando os feedbacks recebidos.

Para as crianças a partir de 3 anos, foi realizada a prova em que era solicitado que o desenho de um triângulo, para que pudesse ser observada a forma com que a criança interpretava o desenho. Ao explorar o recurso tecnológico, foi solicitado que utilizassem para desenhar o aplicativo Desenho para Crianças ${ }^{5}$, este permitia fazer desenhos, apagar e utilizar diferentes cores e formas de carimbos.

As crianças a partir de 4 anos realizaram a prova dos bastonetes ou das réguas, em que bastões de E.V.A deveriam ser organizados em forma de uma escada (crescente). Durante o uso do recurso tecnológico a mesma escada deveria ser montada utilizando o tablet, os bastões ficavam disponíveis e deveriam ser organizados de acordo com o seu tamanho.

Para as crianças de 5 anos a 7 anos, foram oportunizadas duas provas diferentes, a primeira que era a prova dos bastonetes ou réguas e a segunda que era a torre de hanói, em que os discos deveriam ser trocados de torre e organizados de modo que o menor ficasse em cima do maior. Durante a exploração do recurso tecnológico, foi utilizado o aplicativo Tower of $\mathrm{Hanoi}^{6}$, em que as regras eram a mesma da torre original, porém ao movimentar o disco para um lugar impróprio, o mesmo acabava voltando para o lugar de origem, e também era realizada a contagem de movimentações dos discos.

\section{Resultados}

Durante o momento em que as crianças faziam a exploração, procurou-se observar quais os elementos presentes nas tecnologias digitais que ocasionaram mudanças nas suas percepções, possibilitando à elas perceberem coisas de modo mais fácil ao explorar as provas Piagetianas com os recursos digitais do que com o material concreto, deixando evidente as mudanças de Ecologias de Aprendizagem.

Dentre os elementos percebidos ao explorar as tecnologias digitais e que mais chamaram a atenção das crianças, destacam-se: a possibilidade de retomar/iniciar o aplicativo do lugar em que parou, interação proporcionada pelo tablet ou smartphone, tecnologia toque

\footnotetext{
${ }^{1}$ Programação em Scratch: (https://scratch.mit.edu/projects/108193596/)

2 Bichinho interativo para smartphone: (http://www.totetoy.com.br)

3 Aplicativo Classificação - Jogos para crianças

(https://play.google.com/store/www.apps/details?id=.andrey.sorterfree)

${ }^{4}$ Bimi Bo formas e cores (https://play.google.com/store/apps/details?id=com.

bimiboo.playandlearn)

5 Desenho pra crianças: (https://play.google.com/store/apps/details?id=com.iskander.drawforkids)

6 Tower of Hanoi: (https://play.google.com/store/apps/details?id=johan.moller.towerofhanoi)
} 
VIII Congresso Brasileiro de Informática na Educação (CBIE 2019)

Anais dos Workshops do VIII Congresso Brasileiro de Informática na Educação (WCBIE 2019)

tela, interface, feedbacks, desenvolvimento de habilidades cognitivas e motoras, e o grau de atenção dado pela criança durante a exploração.

A tabela 1 apresenta comparações de cada sujeito em uma observação realizada para que as diferenças entre o uso do do material concreto e do recurso tecnológico, e posteriormente as variações entre o manuseio.

\section{Tabela 1. Quadro comparativo com as diferenças entre o uso do material concreto e do recurso tecnológico ${ }^{7}$}

\begin{tabular}{|c|c|c|c|c|}
\hline $\begin{array}{l}\text { Sujeito, } \\
\text { idade }\end{array}$ & $\begin{array}{l}\text { Material } \\
\text { concreto }\end{array}$ & Recurso tecnológico & $\begin{array}{c}\text { Diferenças do material concreto e } \\
\text { do recurso digital }\end{array}$ & Variações durante o manuseio \\
\hline $\begin{array}{l}\text { Sujeito } 1 \\
(0 ; 8)\end{array}$ & $\begin{array}{l}\text { carrinho, } \\
\text { fralda }\end{array}$ & $\begin{array}{l}\text { tablet, programação com } \\
\text { Scratch em que o gato } \\
\text { corria de um lado para } \\
\text { outro emitindo miados e } \\
\text { se escondia em uma das } \\
\text { bolas }\end{array}$ & $\begin{array}{l}\text { material concreto: possibilidade de } \\
\text { pegá-lo; } \\
\text { recurso digital: efeitos visuais, } \\
\text { cores, efeitos sonoros, movimentos, } \\
\text { interação toque tela }\end{array}$ & $\begin{array}{l}\text { conseguiu encontrar o objeto, } \\
\text { logo se interessou pelo tablet, } \\
\text { procurava o gato atrás do } \\
\text { mesmo }\end{array}$ \\
\hline $\begin{array}{l}\text { Sujeito } 9 \\
(4 ; 6)\end{array}$ & $\begin{array}{l}\text { seriação de } \\
\text { bastões de } \\
\text { E.V.A. }\end{array}$ & tablet, seriação de bastões & $\begin{array}{l}\text { material concreto: manipulação, } \\
\text { comparação e visualização em 3D; } \\
\text { recurso tecnológico: interface, } \\
\text { tecnologia toque tela, percepção, } \\
\text { delimitação de espaço (tela) }\end{array}$ & $\begin{array}{l}\text { utilizou o tablet para a prova dos } \\
\text { bastonetes, ressaltou que com o } \\
\text { tablet era mais fácil para poder } \\
\text { arrastar os bastões e compará- } \\
\text { los }\end{array}$ \\
\hline $\begin{array}{l}\text { Sujeito } 11 \\
(5 ; 2)\end{array}$ & torre de hanoi & $\begin{array}{l}\text { tablet e aplicativo da torre } \\
\text { de hanoi }\end{array}$ & $\begin{array}{l}\text { material concreto: manipulação e } \\
\text { visualização em 3D, raciocínio } \\
\text { lógico; } \\
\text { recurso tecnológico: percepção, } \\
\text { raciocínio lógico, contagem dos } \\
\text { movimentos, indicação de jogadas } \\
\text { incorretas, feedbacks }\end{array}$ & $\begin{array}{l}\text { começou passando os discos } \\
\text { sem cuidar as regras do jogo, } \\
\text { precisando ser relembrado, ao } \\
\text { utilizar o app percebia quando } \\
\text { estava fazendo jogadas não } \\
\text { permitidas, querendo jogar } \\
\text { novamente para diminuir o } \\
\text { número de movimentos dos } \\
\text { discos }\end{array}$ \\
\hline $\begin{array}{l}\text { Sujeito } 15 \\
(7 ; 9)\end{array}$ & torre de hanoi & $\begin{array}{l}\text { tablet e aplicativo da torre } \\
\text { de hanoi }\end{array}$ & $\begin{array}{l}\text { material concreto: manipulação e } \\
\text { visualização em 3D, raciocínio } \\
\text { lógico; } \\
\text { recurso tecnológico: percepção, } \\
\text { raciocínio lógico, contagem dos } \\
\text { movimentos, indicação de jogadas } \\
\text { incorretas, feedbacks }\end{array}$ & $\begin{array}{l}\text { com material concreto levou } \\
\text { mais tempo para finalizar o } \\
\text { jogo, precisava ter um adulto } \\
\text { intervindo para relembrar as } \\
\text { regras, com o uso do recurso } \\
\text { tecnológico percebeu como } \\
\text { mover os discos, cuidando para } \\
\text { não realizar movimentos } \\
\text { indevidos, cuidava a contagem } \\
\text { dos movimentos }\end{array}$ \\
\hline
\end{tabular}

Observou-se que, as crianças ao manipular situações com o uso de recurso tecnológico, percebiam as coisas de modo diferente do que quando manipulavam situações idênticas com o uso de materiais concretos, demonstrando ter mais autonomia e iniciativa.

Por exemplo, o sujeito 1 não demonstrou interesse em buscar pelo carrinho que estava escondido e fazendo volume embaixo da sua toalha. Porém quando foi dado para o sujeito o tablet e o gato caminhava emitindo miados e após se escondia, o sujeito prontamente

${ }^{7}$ Devido ao número de sujeitos da pesquisa, e a extensão das informações, foram apresentados neste quadro comparativo apenas as diferenças entre o uso do material concreto e do recurso tecnológico de um número de sujeitos reduzidos com faixas etárias distintas. 
procurava o gato, e chegava a virar o tablet para verificar se ele não estaria escondido na parte de trás da ferramenta.

Verificou-se, também, que as crianças demonstravam preferência por utilizar o recurso tecnológico, pois este muitas vezes fazia referência ao brincar e aos momentos descontraídos que tinham enquanto estavam manipulando à tecnologia, despertando curiosidade em saber o que iríamos explorar.

Para Rogers (2012), esta afinidade justifica-se pelo fato de que as crianças estão imersas em um mundo de mídias interativas e diversos recursos tecnológicos. Em suas casas, na escola e em diferentes lugares, estão acostumadas a utilizar ferramentas digitais, que atualmente já fazem parte da sua cultura.

A partir das observações realizadas com os sujeitos 11 e 15, foi possível verificar que os mesmos ao explorarem o aplicativo Torre de Hanoi logo perceberam que os discos voltavam para o lugar de origem quando uma jogada estava incorreta, bem como, que esta ação incorreta contabilizava manobras de discos e assim, a pontuação iria ser maior do que o número de movimentos previstos pelo aplicativo. O simples fato do disco voltar para o lugar de origem, fazia a criança perceber que ela havia conduzido o disco para o lugar errado e que esta jogada não era permitida, pois ia contra as regras do jogo. No entanto, ao jogar com os discos de madeira, precisavam ser alertada o tempo todo por um adulto, bem como ter o número de movimentações contadas e registradas uma a uma por alguém que tivesse monitorando as jogadas.

Deste modo, a partir das Ecologias de Aprendizagem à luz da exploração das Tecnologias Digitais, observa-se que a criança não necessita de um ambiente formal e rígido para aprender, mais sim, de um ambiente em que sinta-se desafiada, estimulada e que atenda às suas necessidades, de forma intuitiva, lúdica e desafiadora.

Outro fato relevante observado diante da maioria dos sujeitos foi que ao utilizar as Tecnologias Digitais, as provas não necessitavam ser explicadas minuciosamente do que quando realizadas com o material concreto. As crianças já pegavam o tablet em mãos e iam experimentando, verificaram os jogos e percebiam o que era ou não possível fazer.

Dos 16 (dezesseis) sujeitos observados, 1 (um) realiza a exploração no smartphone e 8 (oito) possuem seu próprio tablet, das crianças com faixa etária a partir dos 3 (três) anos, apenas 1 (um) não tinha tablet, as demais estavam habituadas a utilizar a ferramenta e até mesmo conheciam os aplicativos que eram mencionados. Os outros 7 (sete), mesmo não tendo uma ferramenta para uso próprio, conseguiram manipular sem necessitarem de grandes explicações e tiveram sucesso nas explorações.

Em geral, na interação dos sujeitos, foi possível verificar que todos estavam desenvolvendo diferentes capacidades cognitivas, mas também, que a preferência e a atração aconteciam pela forma com que a interface apresentava os aplicativos explorados, pois, conforme Rogers (2012), às experiências com as tecnologias digitais são mais agradáveis e envolventes.

Para todos os 16 (dezesseis) sujeitos, a interface mostrou-se muito importante, pois possibilitou verificar as cores, efeitos visuais, sonoros, visualizar relações espaciais e também temporais, situações estas que nem sempre eram percebidas da mesma forma ao utilizar o material concreto. Outro fator que se demonstrou pertinente para o fato de as crianças optarem por manipular as tecnologias digitais foi que, já haviam utilizado em outros momentos, e assim, a utilização estava associada ao brincar, uma forma de se divertir e uma fonte de entretenimento, situação esta que também é afirmada por Chaudron (2015). 
O uso de ferramentas digitais é algo que faz parte do contexto das crianças, novos objetos interativos apareceram, fazendo com que as mesmas possam ter uma maior interação com estes objetos.

Os objetos fazem uma interlocução com as crianças, ou seja, ao interagir elas recebem uma resposta, o que com objetos reais geralmente não acontece. Os objetos interativos, possuem comportamentos que vão além, proporcionando que elas possam aprender em um ambiente ecológico e interativo, onde estímulos são recebidos em função das suas reações e escolhas ao utilizar as tecnologias digitais.

Adicionalmente à natureza interacionista dos objetos permite que se possa pensar, programar e buscar o desenvolvimento de diferentes habilidades, como visuais e por voz que vão além da utilização penas de um telefone. Estes objetos permitem que se tenha uma maior interação, proximidade e ainda que a criança interaja com o objeto de forma mais dinâmica, aprendendo continuamente.

O uso das tecnologias digitais estava presente no cotidiano das crianças fazendo com que utilizassem de conhecimentos e experiências já adquiridas para dar continuidade à exploração. Adicionalmente, estavam aprendendo de modo não formal, em um ambiente descontraído e interagindo de forma organizada com uma ferramenta que exigia delas estar atenta, utilizar de conhecimentos práticos e também teóricos para dar continuidade às demais situações que eram apresentadas, o que possibilitou às mesmas criar suas próprias Ecologias de Aprendizagem.

\section{Considerações finais}

Ao observar os 16 sujeitos durante o desenvolvimento desta pesquisa, foi possível constatar algumas evidências em relação às Ecologias de Aprendizagem à luz das tecnologias digitais, oportunizando que as crianças se sobressaíssem ao utilizar os recursos tecnológicos e pudessem utilizar desta situação e contexto para favorecer à construção dos seus conhecimentos em um ambiente informal de aprendizagem.

Constatou-se que quando manipularam situações com os recursos tecnológicos as percepções eram diferentes do que quando exploraram as mesmas situações com o uso de material concreto. Pelo olhar das crianças as tecnologias parecem ser mais interessantes, fazendo com que prestassem mais atenção, ficassem mais atentas e buscassem receber feedbacks dos aplicativos, o que não acontecia quando estavam em contato com o material concreto, pois na maior parte das vezes necessitavam do adulto para retomar regras e fazer a contagem de pontuação. Adicionalmente, o uso de tablet, por ser um dispositivo compacto, possibilitou que as crianças pudessem explorá-lo com mais autonomia e desenvoltura.

Deste modo, observa-se mudanças significativas em relação às Ecologias de Aprendizagem quando exploradas à luz das Tecnologias Digitais podendo conduzir a criança a desenvolver-se cognitivamente, ter uma outra visão de mundo a partir da diversidade de oportunidade de exploração, de forma mais agradável e instigante, apresentando suportes a cognição e despertando na criança percepções que o material concreto não possibilita, bem como que a aprendizagem aconteça em diferentes espaços, a partir da exploração das interações com outras pessoas e também com o meio em que está inserida.

\section{Referências}

CETIC, (2017). Pesquisa TIC Kids Online Brasil 2016 - Pesquisa sobre o uso de Internet por crianças e adolescentes no Brasil 2016. Centro Regional de Estudos para o Desenvolvimento da Sociedade da Informação (Cetic.br) do Comitê Gestor da Internet no Brasil (CGI.br). Org: Alexandre Barbosa. São Paulo. 327 pp. 
VIII Congresso Brasileiro de Informática na Educação (CBIE 2019)

Anais dos Workshops do VIII Congresso Brasileiro de Informática na Educação (WCBIE 2019)

CHAUDRON, Stéphane. Young (2015). Children (0-8) and Digital Technology: A qualitative exploratory study across seven countries. JRC Science and polyce reports.

DELVAL, Juan (2002). Introdução à prática do método clínico: descobrindo o pensamento das crianças. Porto Alegre: Artmed.

GOMES, Tancicleide C. S; MELO, Jane C. B; TEDESCO, Patricia C. de A. R (2016). Jogos Digitais no Ensino de Conceitos de Programação para Crianças. V Congresso Brasileiro de Informática na Educação (CBIE 2016), Anais do XXVII Simpósio Brasileiro de Informática na Educação (SBIE 2016), p. 470-479.

JACKSON, N. J. (2013). The Concept of Learning Ecologies. in N Jackson and G B Cooper (Eds). Lifewide Learning, Education and Personal Development E-Book. Chapter A5 available on-line at: http://www.lifewideebook.co.uk/.

JOHNSON; Genevieve Marie (2010). Internet Use and Child Development: Validation of the Ecological Techno- Subsystem. Educational Technology \& Society, 13 (1), 176-185.

LEMKE, J. (1997). Cognition, Context, and Learning: A Social Semiotic Perspective in D. Kirshner and A. Whitson, Eds., Situated Cognition: Social, Semiotic, and Psychological Perspectives, (37-55).

PIAGET, J. INHELDER, B (1985). O desenvolvimento das Quantidades Físicas na Criança: conservação e otimismo. Tradução de Christiano Monteiro Oiticica. 2 edição, Rio de Janeiro, Zahar; Brasília, INL.

PIAGET, J. SZEMINSKA (1975). A gênese do número na criança. Tradução de Christiano Monteiro Oiticica. $2^{\text {a }}$ ed. Rio de Janeiro, Zahar; Brasília, INL.

SILVA; Patrícia Fernanda da (2017). O uso das Tecnologias Digitais com crianças de 7 meses a 7 anos : Como as crianças estão se apropriando das Tecnologias Digitais na Primeira Infância? Tese de Doutorado, UFRGS, Centro de Estudos Interdisciplinares em Novas Tecnologias na Educação, PPGIE, Porto Alegre, RS, 232f.

ROGERS; Fred (2012). Technology and Interactive Media as Tools in Early Childhood Programs Serving Children from Birth through Age 8. Positions State Ment Adopt, Ed, January. 